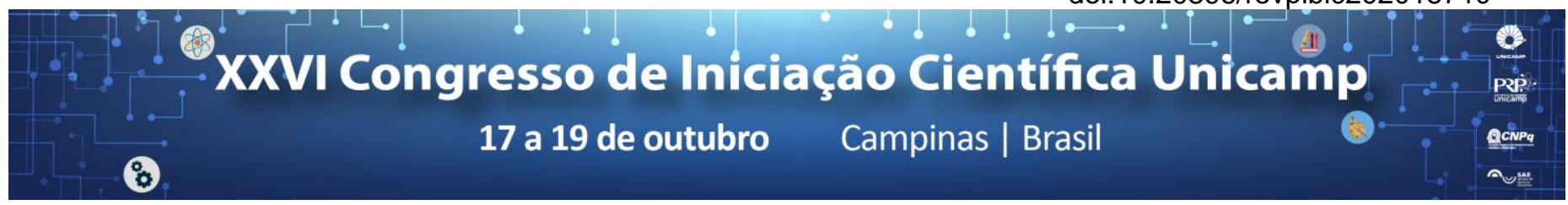

\title{
Estudo sobre a influência dos aplicativos de celulares no processo de aquisição da linguagem
}

\section{Julia Franco*, Prof. Dr. Pablo Faria}

\section{Resumo}

Esta pesquisa investigou os impactos dos aplicativos de celulares e tablets como fornecedores de dados linguísticos no processo de aquisição lexical de crianças entre 2 e 3 anos. Foram estabelecidos critérios de análise a partir de estudos teóricos ancorados na teoria da Gramática Gerativista e, a partir deles, foram analisados onze aplicativos para o sistema Android. Observou-se que os aplicativos oferecem diferentes meios de contato lexical e situações de aprendizagem, influenciando o processo de aquisição de diversas maneiras.

\section{Palavras-chave:}

Aquisição da linguagem, inatismo, aplicativos de celular.

\section{Introdução}

Segundo a teoria inatista de Noam Chomsky, a criança possui capacidade inata de adquirir linguagem ${ }^{1}$. Apesar de dotada dessa capacidade, é necessário que a criança seja exposta a dados da língua, inputs, que forneçam informações que coloquem em marcha tal processo. Propõe-se, assim, refletir sobre o impacto dos aplicativos de celulares como fornecedores de dados linguísticos para a aquisição lexical. Nesse sentido, discutem-se os diferentes tipos de evidência (evidência positiva, negativa e negativa indireta, cf. Valian $\left.{ }^{2}, 1999\right)$; as tendências que têm papel na aquisição lexical (assunções de exclusividade mútua, taxonômica e do objeto inteiro, cf. Markman ${ }^{3}$, 1989) e, ainda, analisam-se aspectos gráficos pertinentes dos aplicativos.

\section{Resultados e Discussão}

Como objetivo principal desta pesquisa, buscouse definir critérios de análise dos aplicativos a partir da teoria da aquisição da linguagem no que diz respeito à aquisição lexical, principalmente. Assim, os aplicativos foram avaliados quanto a sua relação com os seguintes critérios: (i) as tendências definidas por Markman (1989); (ii) a incompatibilidade referencial entre os elementos gráficos, incluindo imagens em segundo plano; (iii) os conceitos alvo da aprendizagem selecionados pelo aplicativo; (iv) a hierarquia de inclusão de classe (p.e. cachorro > animal) e (v) as noções de tipos de evidências (Valian, 1999).

Definidos os critérios, onze aplicativos foram avaliados. Para fins de ilustração tomamos o aplicativo Primeiras Palavras (Papumba). A Figura 1 ilustra a atividade de aprendizagem das cores, neste caso a cor preta. Diante dessa imagem é reproduzido o enunciado "O escaravelho é preto". Nota-se que há uma disparidade entre os elementos gráficos e o enunciado, pois o que é exibido não é um escaravelho, mas um monstrinho. Há elementos que rementem à cor preta, mas não ao escaravelho $e$ isso pode levar a criança a estender incorretamente a palavra "escaravelho" ao monstrinho. A falta de um referente para a palavra que o representa cessa a possibilidade de evidência positiva e a criança passa a ter que mobilizar seu conhecimento de mundo para atribuir sentido a eles. Como a cor preta só é acessível pela criança por intermédio do monstrinho, a imagem poderia ser repensada para destacar a propriedade de modo mais independente do referente, utilizando, por exemplo, uma figura mais próxima do enunciado, como um escaravelho, ou, ainda, mudando o enunciado para "Este monstrinho é preto", de forma a destacar os elementos da imagem.

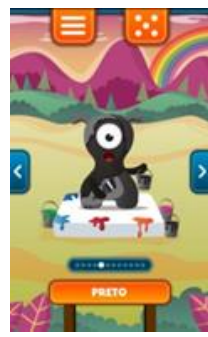

Figura 1: Imagem correspondente à frase "O escaravelho é preto"

Questionam-se, ainda, a escolha do conceito "escaravelho". Sabe-se que as palavras mais consolidadas no acervo lexical são recordadas mais facilmente (Luria ${ }^{4}$, 1987). Quanto mais a criança puder vincular uma nova palavra a fatores presentes no seu acervo de conhecimento, mais fácil ela irá adquiri-la. Assim, acreditase que o uso de "escaravelho" na atividade poderia ser substituído por "pneu", uma vez que a probabilidade deste último estar presente no input da criança é maior do que o primeiro, na maioria dos casos.

\section{Conclusões}

Nessa pesquisa, levantamos critérios que permitem uma análise qualitativa de aplicativos de celulares de acordo com as teorias de aquisição da linguagem. No futuro, as propriedades destes aplicativos podem ser investigadas experimentalmente utilizando metodologias da área de aquisição da linguagem.

\section{Agradecimentos}

Agradeço ao CNPq/Pibic pelo apoio financeiro, ao meu orientador Prof. Dr. Pablo Faria e, ainda, à empresa Papumba por ceder o acesso gratuito completo ao aplicativo Primeiras Palavras.

\footnotetext{
${ }^{1}$ GROLlA, E. \& FIGUEIREDO, M. C. Para conhecer: Aquisição da linguagem. São Paulo: Contexto, 2014.

${ }^{2}$ VALIAN, V. "Input and Language Acquisition". In RITCHIE, W. C. \& BHATIA, T. K. (orgs.). Handbook of Child Language Acquisition. New York: Academic Press, 1999.

${ }^{3}$ MARKMAN, E. M. Categorization and Naming in Children: Problems of Induction. Cambridge: MIT, 1989.

${ }^{4}$ LURIA, A. R. Pensamento e linguagem: As últimas conferências de Luria. Porto Alegre: Artes Médicas, 1987.
} 